\title{
Free Surface Sloshing Effect on Dynamic Response of Rectangular Storage Tanks
}

\author{
H. Mirzabozorg ${ }^{1, *}$, M. A. Hariri-Arde bili ${ }^{2}$, R. Nateghi A. ${ }^{1}$ \\ ${ }^{1}$ Department of Civil Engin eering, K. N. Toosi University of Technology, Tehran, 15875-4416, Iran \\ ${ }^{2}$ Department of Civil, Environmental and Architectural En gineering, University of Colorado, Boulder, 80309-0428, USA \\ mohammad.haririardebili@colorado.edu,r_nateghi@sina.kntu.ac.ir
}

\begin{abstract}
Dynamic analysis of liquid storage tanks is one of interesting subjects in the earthquake engineering. In the present paper, the staggered displacement method is utilized for analysing concrete storage tanks. In the proposed method, surface sloshing of the liquid domain is considered in addition to the effect of impulsive component of the liquid on the structure response. Also, different damp ing coefficients are applied on the various components of the liquid. Foundation is assumed to be rig id and an artificial dynamic load as well as a real ground motion record are used to analyse the tank-liquid coupled system in time domain. The resulted response is compared with those obtained from the commercial software. It is found that the convective term affects responses extensively and must be considered in seismic safety analysis of storage tanks.
\end{abstract}

Keywords Fluid-Structure Interaction, Free-Surface Sloshing, Hydrodynamic Pressure, Liquid Storage Tank

\section{Introduction}

Liquid storage tanks are important components of lifeline and industrial facilities. Failure of tanks especially in the case of storing combustible and perilous materials can lead to extensive disasters. Tanks maybe divided into various categories based on their material, shape, support type and etc. Fig. 1 shows various classifications identified for liquid storage tanks. Several researchers have investigated on liquid storage tanks behaviour in static and dynamic conditions considering simplified assumptions and also, features such as fluid-structure interaction and surface sloshing.

Housner (1963)[1] introduced a simple mechanical analogue of tank-liquid system. Effect of shell flexibility on hydrodynamic pressure and fluid-structure interaction was studied by Haroun et al. (1982)[2] and Vetelsos (1984)[3]. These studies led to development of mechanical analogues for flexible tanks, which are also being used in design codes. With the recent developments in computing machines and numerical methods, refined analyses of tank-liquid system have been performed. There are also some experimental studies on dynamic response of these coupled system such as Haroun et al. (1982)[2], Jaiswal et al. (2008)[4] and Damatty et al. (2000)[5]. Koh et al. (1998)[6] introduced a coupled BEM-FEM including free-surfacesloshing motion to analyse three-dimensional rectangular storage tanks

* Corresponding author:

mirzabozorg@kntu.ac.ir (H. Mirzabozorg)

Published online at http://journal.sapub.org/ajfd

Copyright (C) 2012 Scientific \& Academic Publishing. All Rights Reserved subjected to horizontal ground excitation. Chen and Kianoush (2004)[7] developed a procedure called the sequential method for computing hydrodynamic pressures in two-dimensional rectangular tanks in which the effect of flexibility of the tank wall is taken into account. Also, Kianoush and Chen (2004)[8] investigated the response of concrete rectangular liquid storage tanks subjected to vertical ground acceleration. Ghaemian et al. (2005)[9] and Kianoush et al. (2006)[10] investigated 3D dynamic analysis of liquid storage tanks considering sloshing effects under natural ground motion records. Grad inscak et al. (2006)[11] studied sloshing effects on rectangular tanks with flexible walls. Livaoglu and Dogangun (2006)[12] introduced a simplified method for analysis of elevated tanks considering soil-structure-fluid interaction effects. Don and Redekop (2007)[13] studied free vibration and nonlinear analysis of cylindrical tanks with different ratio of radius to height. Goudarzi and Sabbagh-Yazdi (2008)[14] studied finite element analysis of circular steel storage tanks under uni-directional and multi-d irectional earthquake loads using ANSYS software considered sloshing effects. Shahverdiani et al. (2008)[15] investigated behaviour of concrete cylindrical storage tanks under harmonic dynamic loads. They found that there is a value for wall thickness to tank diameter ratio, which can be used as a guide in considering the wall flexibility effects. Naderi et al. (2011)[16] investigated the effects of soil- buried tank-liquid interaction under several earthquake ground motions. They used ABAQUS software in order to analyse the buried rectangular concrete storage tanks. James and Thanigaiarasu (2011)[17] used mathematical approach for seismic analysis of cylindrical 
storage tanks under horizontal ground acceleration and compared the results with those obtained from ANSYS software. Alembagheri and Estekanchi (2011)[18] used the endurance time analys is method for seismic analysis of steel storage tanks considering sloshing effects.

In the present paper, staggered displacement method is used in order to solve the coupled liquid-tank problem considering free surface sloshing effects. This method is able to consider both convective and impulsive components in dynamic analysis. For this purpose a plane-coupled system was provided and excited using artificial and natural ground motions records in both horizontal and vertical directions. Results were compared with those obtained from ABAQUS software.

\section{Governing Equation in Liquid Domain}

The governing equation of motion in liquid contained in a tank is given as:

$$
\nabla^{2} p=0
$$

In order to solve the above equation using the finite element technique a set of appropriate boundary conditions are required as discussed in following sections.

\subsection{Boundary Condition at Liquid-Tank Inter face}

At the interface of liquid and tank, there is no flow. The appropriate boundary condition on the interface is given as:

$$
\frac{\partial p}{\partial n}=-\rho a_{n}^{s}
$$

in which, $n$ and $a_{n}{ }^{s}$ are outwardly normal direction to the tank wall and normal acceleration applied on the liquid at the interface, respectively.

\subsection{Boundary Condition at Free Surface}

Considering small amplitude gravity waves on the free surface of liquid, the resulting boundary condition is given as:

$$
\frac{1}{g} \frac{\partial^{2} p}{\partial t^{2}}+\frac{\partial p}{\partial z}=0
$$

in which, $z$ is vertical direction and $g$ is acceleration gravity.

\subsection{Discretized Equation of Liquid Domain}

Using Galerkin's technique, the discretized finite element governing equation of motion in liquid domain is given as:

$$
[G]\{P\}+\left[C_{f}\right]\{P\}+\left[K_{f}\right]\{P\}=\{F\}
$$

in which,

$$
\begin{aligned}
& G_{i j}^{e}=\frac{1}{g} \int_{A_{i}} N_{i} N_{j} d A \\
& H_{i j}^{e}=\int_{V}\left(\frac{\partial N_{i}}{\partial x} \frac{\partial N_{j}}{\partial x}+\frac{\partial N_{i}}{\partial y} \frac{\partial N_{j}}{\partial y}+\frac{\partial N_{i}}{\partial z} \frac{\partial N_{j}}{\partial z}\right) d v \\
& \{F\}=\left\{F_{i}\right\}-\rho[Q]^{T}\left(\{\ddot{U}\}+\left\{\ddot{U}_{g}\right\}\right) \\
& F_{i}^{e}=\int_{A_{i}} N_{i} \frac{\partial P}{\partial n} d A
\end{aligned}
$$

where $N_{i},\{\ddot{U}\},\left\{\ddot{U}_{g}\right\},[Q]$ and $\left[C_{f}\right]$ are shape function of the $i^{\text {th }}$ node in the liquid element, acceleration vector of nodes in the structure domain, ground acceleration vector applied on the system, coupling matrix and finally, damping matrix of the liquid domain, respectively.

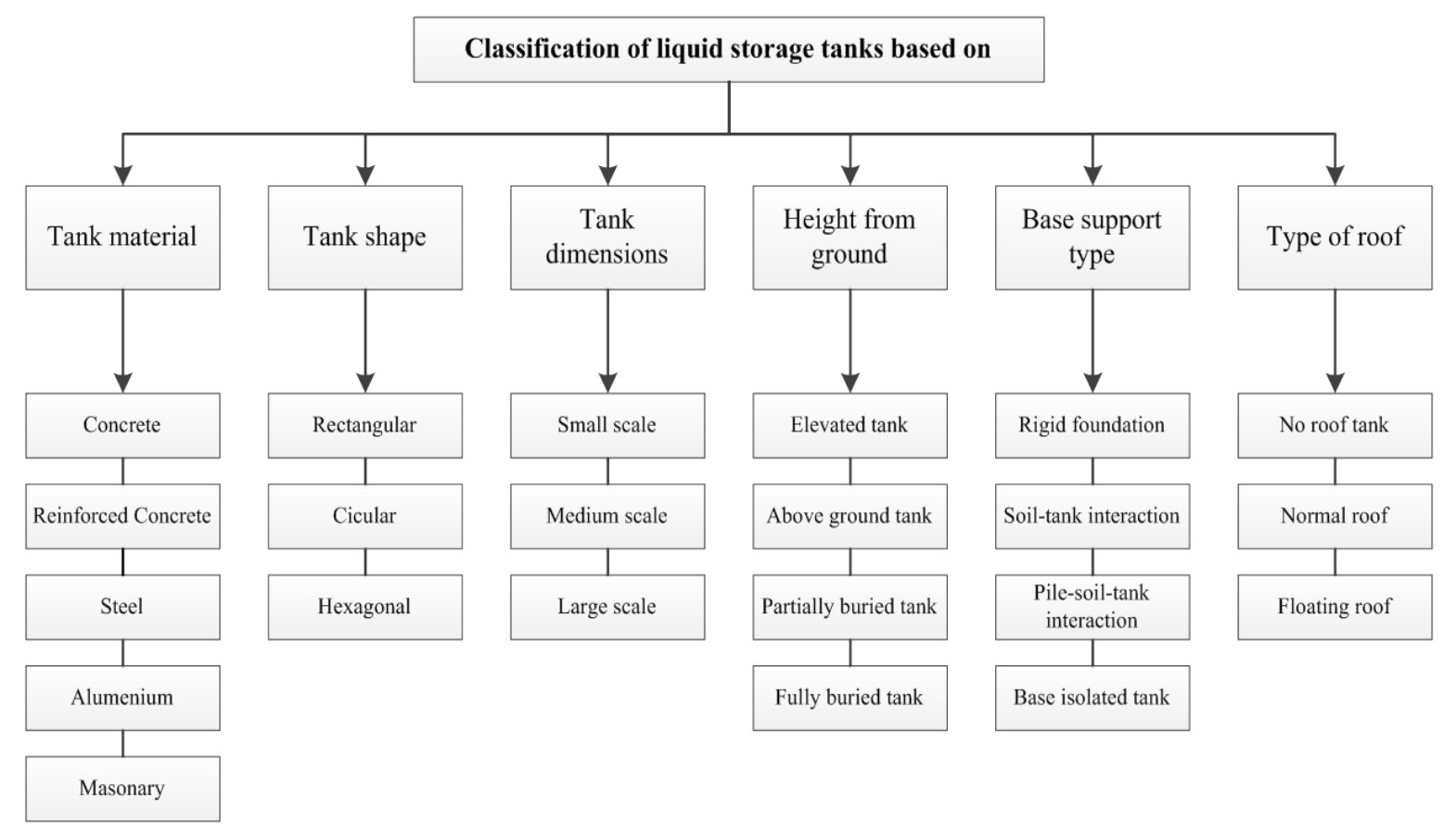

Figure 1. Classification of liquid storage tanks 


\subsection{Coupling Matrix}

The coupling matrix, $[Q]$ transfers pressures applied on the liquid-wall interface as nodal forces to the tank walls. In the present paper, this matrix is generated by proportional lumping method. For eight node interface elements with $\mathrm{x}$, $y$ and $z$ translational DOF at each node on the face of the tank wall and corresponding four node interface elements with pressure DOF at each node attached to the liquid element, the coupling matrix is given as (Eq.6):

$$
[Q]=\omega \int_{-1-1}^{1} \int_{1=1}^{1}\left[\begin{array}{cccc}
\alpha_{1} N_{1}^{s} N_{1}^{s} N_{1}^{f} & & \alpha_{1} N_{1}^{s} N_{1}^{s} N_{4}^{f} \\
\beta_{1} N_{1}^{s} N_{1}^{s} N_{1}^{f} & \cdots & \beta_{1} N_{1}^{s} N_{1}^{s} N_{4}^{f} \\
\gamma_{1} N_{1}^{s} N_{1}^{s} N_{1}^{f} & & \gamma_{1} N_{1}^{s} N_{1}^{s} N_{4}^{f} \\
\alpha_{8} N_{8}^{s} N_{8}^{s} N_{1}^{f} & \ddots & \alpha_{8} N_{8}^{s} N_{8}^{s} N_{4}^{f} \\
\beta_{8} N_{8}^{s} N_{8}^{s} N_{1}^{f} & \ldots & \beta_{8}^{s} N_{8}^{s} N_{8}^{s} N_{4}^{f} \\
\gamma_{8} N_{8}^{s} N_{8}^{s} N_{1}^{f} & & \gamma_{8}^{8} N_{8}^{s} N_{8}^{s} N_{4}^{f}
\end{array} \|_{24 \times 4}\right.
$$

in which,

$$
\begin{aligned}
& \vec{t}_{\xi}=\left\{\frac{\partial x}{\partial \xi}, \frac{\partial y}{\partial \xi}, \frac{\partial z}{\partial \xi}\right\}^{T} \\
& \vec{t}_{\eta}=\left\{\frac{\partial x}{\partial \eta}, \frac{\partial y}{\partial \eta}, \frac{\partial z}{\partial \eta}\right\}^{T} \\
& \omega=\frac{A}{\sum_{i=1}^{8} \int_{A_{e}} N_{i}^{s} N_{i}^{s}\left\|t_{\xi} \times t_{\eta}\right\| d \xi d \eta} \\
& A=\int_{A_{e}}^{\int}\left\|_{\xi} \times t_{\eta}\right\| d \xi d \eta
\end{aligned}
$$

where, $N^{f}$ and $N^{s}$ are the shape functions in liquid and structure domains, respectively.

\subsection{Damping within the Liquid Domain}

The damping matrix within the liquid domain includes two terms originating from impulsive and convective parts of the liquid doma in as follows:

$$
\left[C_{f}\right]=a[G]+b\left[K_{f}\right]
$$

in which $a$ and $b$ are computed based on Ryliegh damping. Parameter $a$ is computed based on the fundamental vibration frequency of the free surface waves and $b$ is computed based on the fundamental frequency of the tank walls.

\section{Coupled Equations of the Tank and Liquid}

The tank-liquid problem is a classical coupled problem, which contains two second order differential equations. The equations of the tank and the liquid are written in the following form:

$$
\begin{aligned}
& {[M]\{\ddot{U}\}+[C]\{\dot{U}\}+[K]\{U\} } \\
& =\left\{f_{1}\right\}-[M]\left\{\ddot{U}_{g}\right\}+[Q]\{P\}=\left\{F_{1}\right\}+[Q]\{P\} \\
{[G]\{\ddot{P}\}+[C] } & {[\dot{P}\}+\left[K_{f}\right]\{P\} } \\
= & \{F\}-\rho[Q]^{T}\left(\{\ddot{U}\}+\left\{\ddot{U}_{g}\right\}\right)=\left\{F_{2}\right\}-\rho[Q]^{T}\{\ddot{U}\}
\end{aligned}
$$

The direct integration scheme reported in Mirzabozorg et al. (2003)[19] is used to find the displacement and hydrodynamic pressure at the end of the time increment $i+1$, given the displacement and hydrodynamic pressure at time $i$.

\section{Finite Element Implementation of the Proposed Model}

A twenty-node iso-parametric element is used in finite element implementation of the tank walls. The stiffness matrix and all of the other related components are based on $3 \times 3 \times 3$ Gaussian integration points in the structure domain. The liquid domain is modelled using eight-node iso-parametric flu id elements with $2 \times 2 \times 2$ Gaussian integration points. For the interface elements between the structure and the liquid, $3 \times 3$ Gaussian integration points are used and for the other surface elements on the boundary of liquid, $2 \times 2$ Gaussian integration points are emp loyed.

\subsection{Developing a Numerical Model}

A one meter strip of the tank wall is modelled to simu late the two dimensional behaviour of the system. The general view of the tank-liquid system and also the corresponding fin ite element model are shown in Fig.2. The finite element discretization of the system includes 52 twenty-node solid elements for modelling the tank walls and 240, eight-node flu id elements for modelling the liquid domain. The dimensions and properties of the considered coupled system are summarized in Table.1.

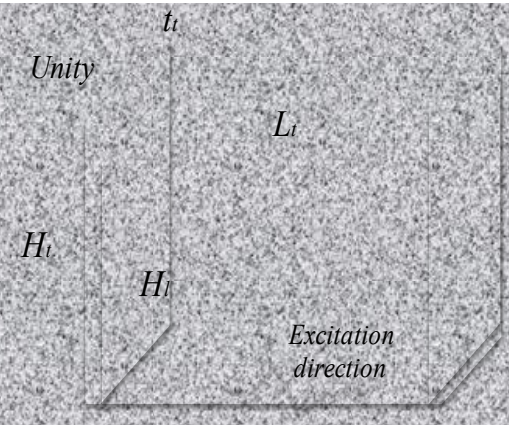

Rigid base

(a)

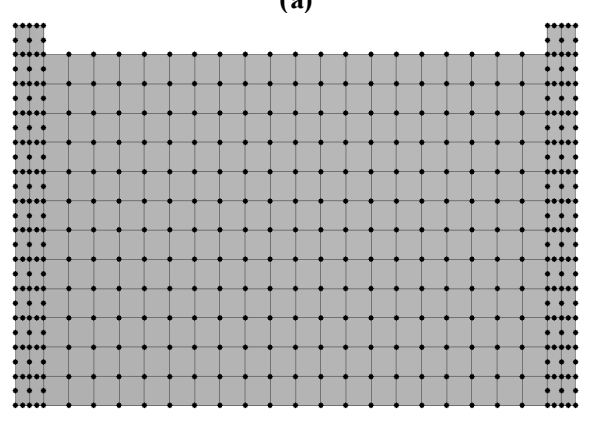

(b)

Figure 2. Two dimensionalmodel of tank-liquid system (a) General view; (b) Finite element discretization of the coupled system 
Table 1. Dimensions and properties of tank and liquid domain

\begin{tabular}{cc}
\hline Tank Domain & Liquid Domain \\
\hline Mass density $\rho_{t}=25000 \mathrm{~N} / \mathrm{m}^{3}$ & Mass density $\rho_{l}=9807 \mathrm{~N} / \mathrm{m}^{3}$ \\
Modulus of elasticity $E_{t}=27.39 * 10^{9} \mathrm{~N} / \mathrm{m}^{2}$ & Sound velocity $C=1438 \mathrm{~m} / \mathrm{s}$ \\
Poisson's ratio $v=0.17$ & Liquid height $H_{l}=6.0 \mathrm{~m}$ \\
Tank height $H_{t}=6.5 \mathrm{~m}$ & \\
Tank length $L_{t}=20.0 \mathrm{~m}$ & \\
Tank thickness $t_{t}=0.50 \mathrm{~m}$ & \\
\hline
\end{tabular}

\subsection{Loading the Coupled System}

The applied loads on the tank are self-weight, hydrostatic pressure and dynamic loads. Two different scenarios were considered for dynamic analys is of the coupled system; i.e. using artificial dynamic load; and using natural ground motion record. In the first case, a simple time stepped load was used in which its amplitude and phase change every $5 \mathrm{~s}$. The time-history of acceleration for artificial dynamic load is shown in Fig. 3.

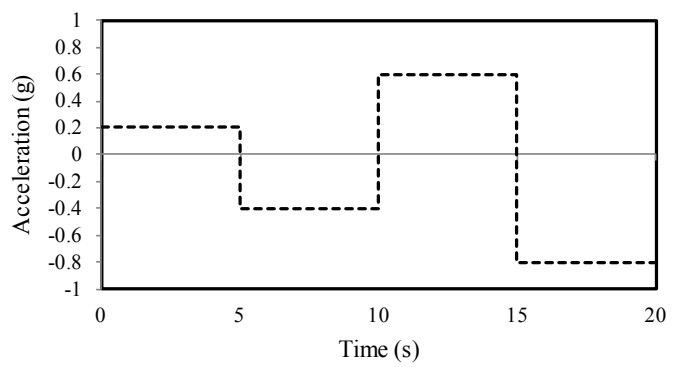

Figure 3. Acceleration time-history of artificial dynamic load
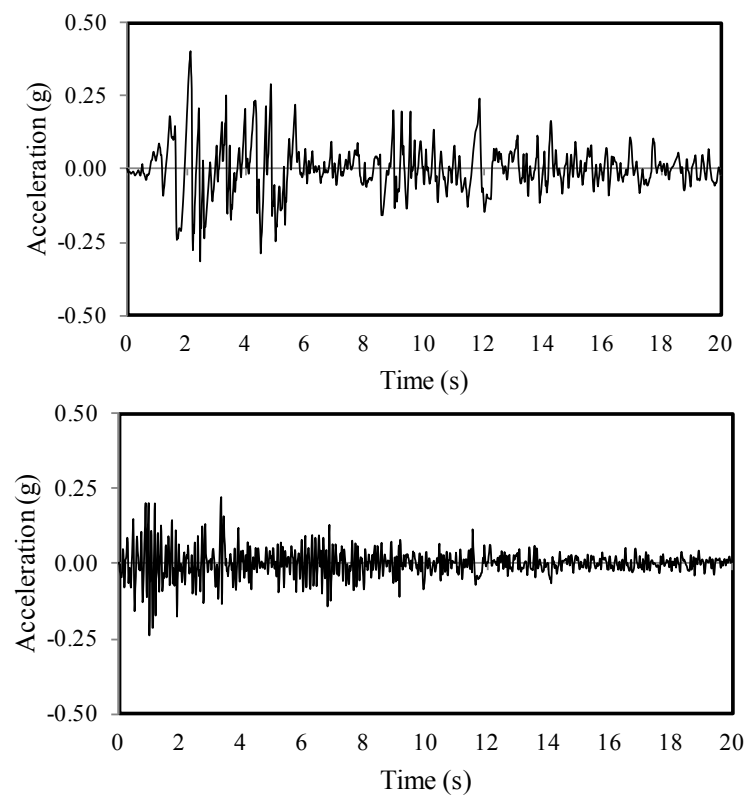

Figure 4. Scaled accelerat ion time-hist ory of El-Centro ground motion;(a) Horizontal component; (b) Vertical component

For the second case, the horizontal and vertical components of the earthquake recorded for El-Centro 1940 were selected to be used. The peak ground acceleration (PGA) of this ground motion is $0.348 \mathrm{~g}$ in horizontal direction. Both horizontal and vertical component were scaled in such a way that the PGA in horizontal component is $0.40 \mathrm{~g}$ (for comparison with artificial dynamic load) and in vertical component is $0.24 \mathrm{~g}$. The ground accelerations for horizontal and vertical components are shown in Fig.4. The responses of the system under natural ground motion record are computed for both the horizontal and vertical directions separately and also due to comb ination of the two components. It's worthy to note that for the dynamic analysis of the system using natural ground motion only first 10 s of the selected record was used.

It's noteworthy that the time integration step was $0.005 \mathrm{~s}$ in the conducted analyses. The Rayleigh damping was used in the direct step-by-step integration method. The stiffness proportional damping equivalent to $5 \%$ of critical damping was used as structural damping and for the convective and impulsive components of the stored liquid, $0.5 \%$ and $5 \%$ of critical damp ing was applied, respectively.

\section{Results and Discussion}

\subsection{Artificial Dynamic Load}

In this section, results obtained from excitation of tank-liquid system using artificial dynamic load are investigated and compared with those obtained from ABAQUS 6.5.1 software[20]. It's noteworthy that the similar finite element model, boundary conditions and material properties were used in ABAQUS software. In the model utilized at this commercial finite element program, just impulsive term in dynamic analysis of the coupled fluid-structure system was considered and convective term was neglected.

Fig. 5 shows displacement time-history of the tank top point in horizontal direction obtained from ABAQUS and proposed method without considering convective term effects. As it is clear, there is good consistency between the two methods neglecting sloshing effects. Fig.6 shows displacement time-history in horizontal and vertical directions for empty and full tanks with and without considering convective term effects. As can be seen, neglecting sloshing effects leads to damping of the motion with almost constant ratio while considering convective term increases results and leads to fluctuation the imposed motion. In addition, Fig. 7 shows time-history of free surface sloshing in the considered problem. As can be seen, the liquid experiences sloshing about $0.21 \mathrm{~m}, 0.58 \mathrm{~m}, 1.05 \mathrm{~m}$ and $1.62 \mathrm{~m}$ under dynamic accelerations equal to $0.2 \mathrm{~g}, 0.4 \mathrm{~g}, 0.6 \mathrm{~g}$ and $0.8 \mathrm{~g}$ respectively.

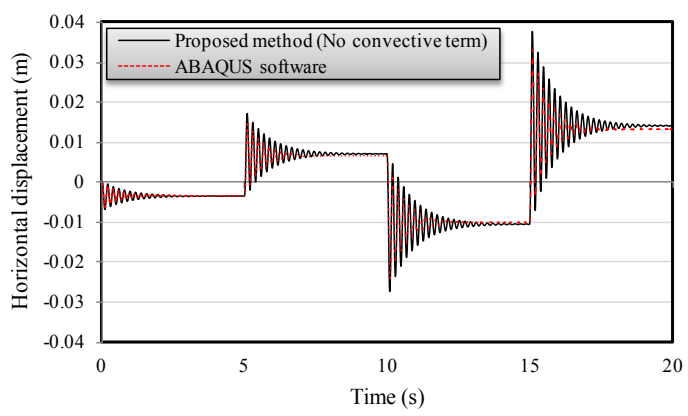

Figure 5. Comparison of horizontal displacement in ABAQUS software and proposed method without convect ive term effect 


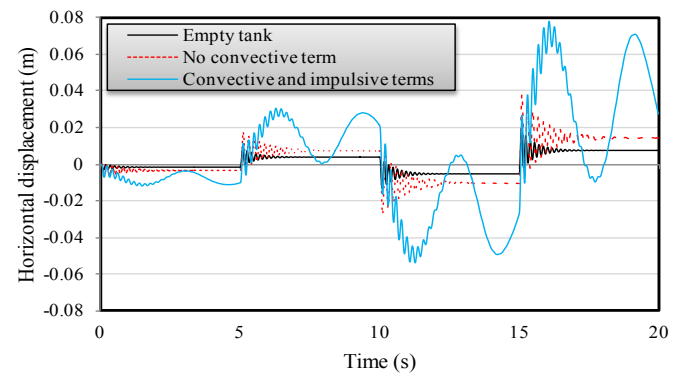

(a)

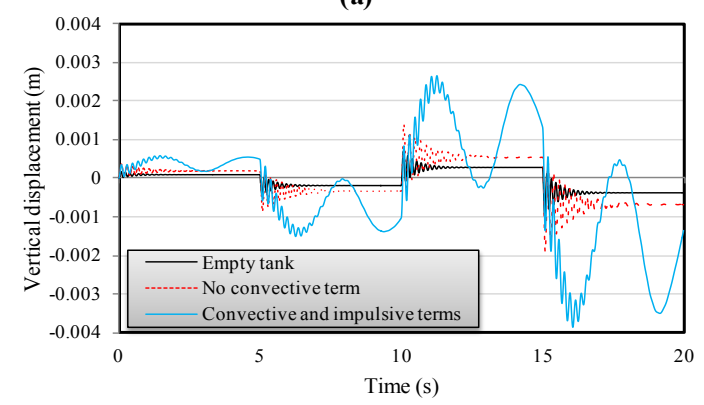

(b)

Figure 6. Time-history of displacement using the proposed method in three various conditions (a) Horizontal displacement; (b) Vertical displacement

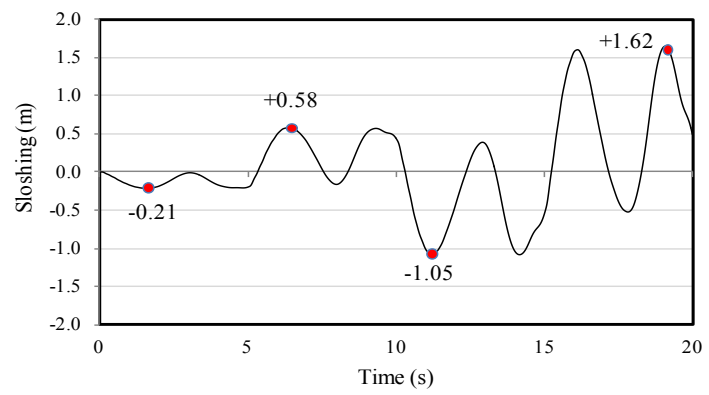

Figure 7. Time-history of the height of free surface sloshing under artificial excitation

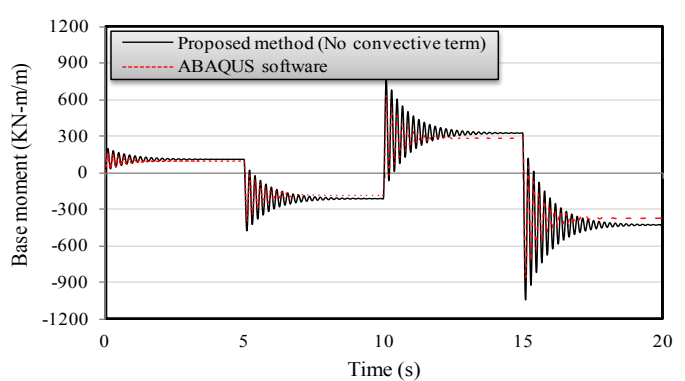

(a)

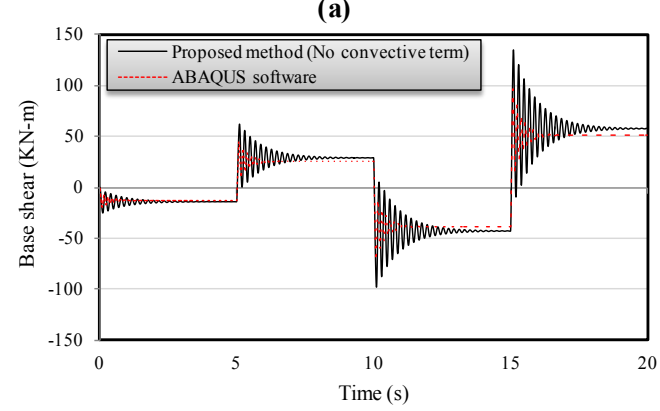

(b)

Figure 8. Comparison of (a) base moment and (b) base shear in ABAQUS software and proposed method without convective term effect
Fig. 8 compares the base shear and base mo ment obtained from the proposed method excluding convective term with those obtained from ABAQUS. Although the general trends are the same in two methods, the result of base shear shows more differences than the base moment. Fig.9 presents time-history of the base shears and base moments for empty and full tanks with/without the effects of convective term. In both cases considering sloshing at the free surface leads to completely different results.

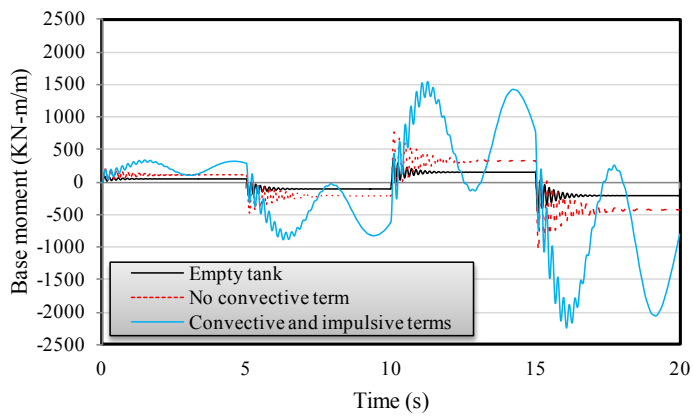

(a)

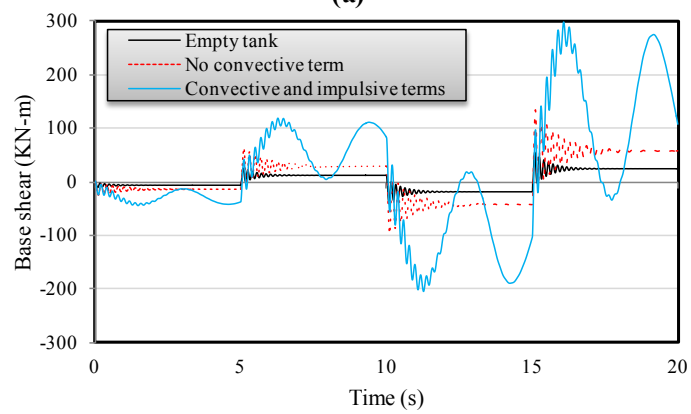

(b)

Figure 9. Time-history of (a) base moment and (b) base shear using the proposed method in three various conditions

\subsection{Natural Earthquake Load}

In this section, the results of analysis of the provided tank-liquid finite element model excited using scaled El-Centro ground motion are studied. Three loads combinations were investigated in the present study; in the first one only horizontal component; in the second one only vertical component and; in the third analysis both components of the scaled ground motion were used for seismic analysis. Figures pertinent to the third load combination are presented herein and the results of other analyses are summarized tabular. Fig. 10 shows time-history of the horizontal displacement at top of the tank wall. As it is clear, taking into account convective term leads to higher displacements. In addition ABAQUS software gives close result to those obtained from the proposed method when excluding surface sloshing effects. Similar plots for base shear and base moment are shown in Fig. 11. These time-histories are in good agreement with the results obtained based on the displacement time history as mentioned before.

Fig. 12a represents time-history of free surface sloshing. As can be seen, maximum sloshing is $0.12 \mathrm{~m}$. Fig. $12 \mathrm{~b}$ shows the distribution of hydrodynamic pressure along the height of the tank wall at the time of maximum surface sloshing so 
that hydrodynamic pressure at level of $6.0 \mathrm{~m}$ is extreme with the value of $1155 \mathrm{~Pa}$ and at level of $3.0 \mathrm{~m}$ its value is lowest and equals to $774 \mathrm{~Pa}$.

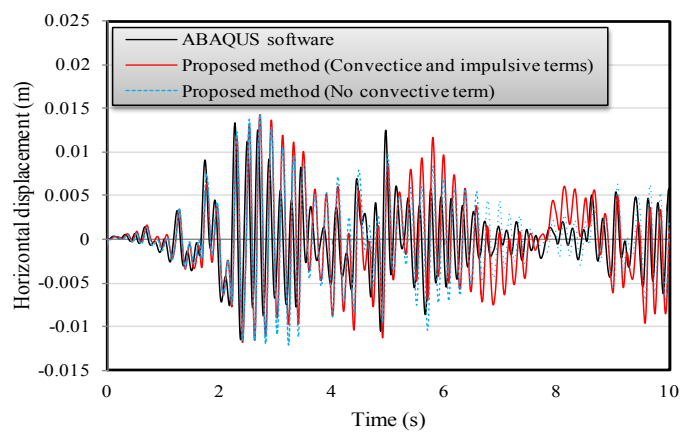

Figure 10. Time-history of displacement in horizontal direction under bi-component excitation

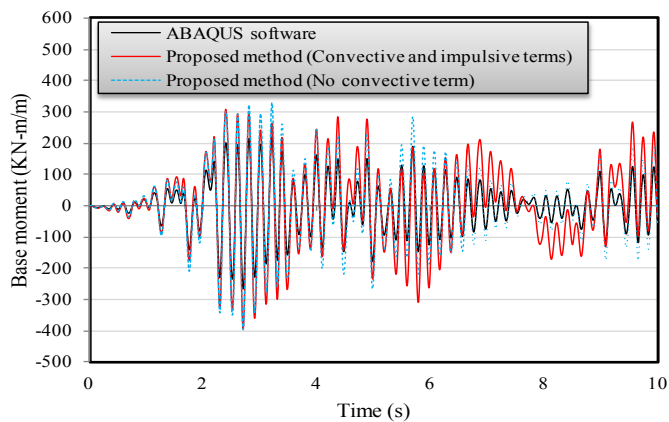

(a)

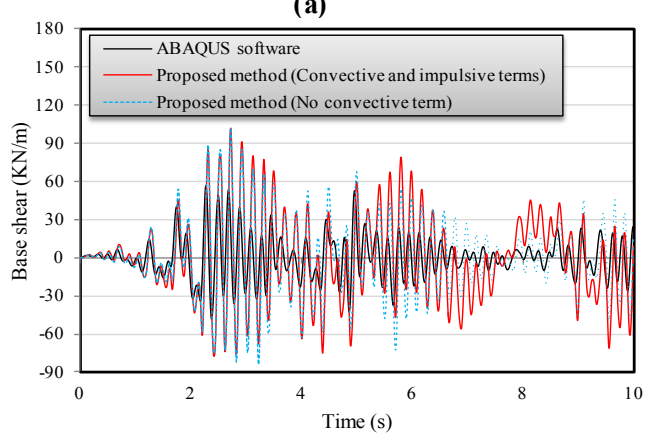

(b)

Figure 11. Time-history of (a) base moment and (b) base shear using the proposed method and ABAQUS soft ware under bi-component excitation

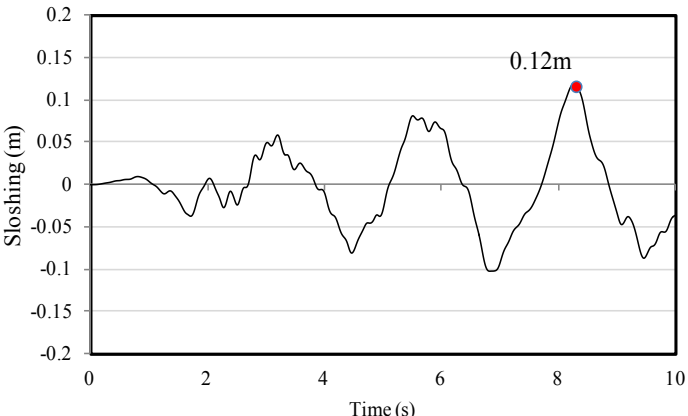

(a)

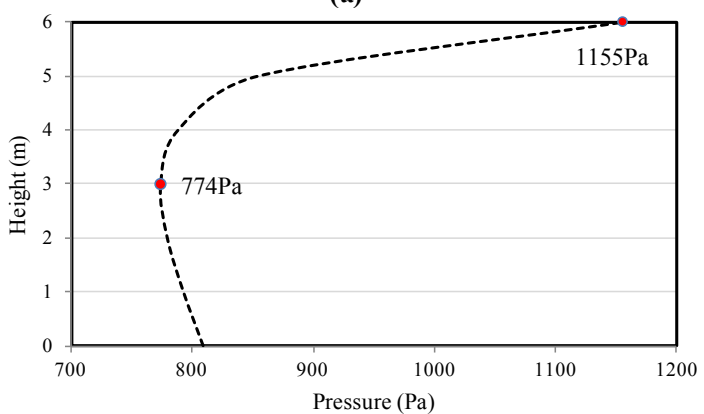

(b)

Figure 12. (a) Time-history of free surface sloshing, (b) Distribution of hydrodynamic pressure along the height of tank wall at time of maximum surface sloshing

Tables 2 to 4 summarize results of the conducted dynamic analyses. Based on these tables, analys is of the system using only vertical component of the ground motion has no effect on the horizontal displacement resulted from the cas es with/without considering convective term effects, while adding horizontal component of the ground motion leads to increasing horizontal displacement and neglecting convective term shows a little more drift in this condition. In addition, using bi-combination excitation leads to lower results than the case with only horizontal component of the earthquake. The same results can be seen for total base moment and base shear. For these responses the horizontal component of the ground motion has meaningful effect on maximum values. The maximum height of surface sloshing is the same for cases using only horizontal component and bi-component excitation, while the sloshing in the case of vertical component is very small.

Table 2. Summarized results of analysis of the system excited horizontally

\begin{tabular}{|c|c|c|c|}
\hline \multirow{2}{*}{ Results } & \multirow{2}{*}{ Empty tank } & \multicolumn{2}{|c|}{ Full tank } \\
\hline & & No convective term & Sloshing effect \\
\hline Horizontal displacement(mm) & $5.6 /-5.5^{*}$ & $15.6 /-12.8$ & $15.4 /-13.0$ \\
\hline Total base moment $(\mathrm{KN}-\mathrm{m} / \mathrm{m})$ & $144 /-143$ & $359 /-425$ & $350 /-421$ \\
\hline Total base shear(KN/m) & $35 /-35$ & $108 /-89$ & $107 /-88$ \\
\hline Sloshing height $(\mathrm{mm})$ & & & $118 /-102$ \\
\hline Impulsive base shear $(\mathrm{KN} / \mathrm{m})$ & & & $92 /-85$ \\
\hline Convect ive base shear $(\mathrm{KN} / \mathrm{m})$ & & & $27 /-27$ \\
\hline Impulsive base moment $(\mathrm{KN}-\mathrm{m} / \mathrm{m})$ & & & $346 /-374$ \\
\hline Convective base moment(KN-m/m) & & & $107 /-107$ \\
\hline
\end{tabular}

${ }^{*}$ The(-) sign indicates the response of system in opposite side of axis 
Table 3. Summarized results of analysis of the system excited vertically

\begin{tabular}{|c|c|c|c|}
\hline \multirow{2}{*}{ Results } & \multirow{2}{*}{ Empty tank } & \multicolumn{2}{|c|}{ Full tank } \\
\hline & & No convect ive term & Sloshing effect \\
\hline Horizontal displacement(mm) & $0.0 / 0.0$ & $4.3 /-5.0$ & $4.3 /-5.0$ \\
\hline Total base moment $(\mathrm{KN}-\mathrm{m} / \mathrm{m})$ & $2.0 /-3.0^{*}$ & $145 /-120$ & $144 /-117$ \\
\hline Total base shear(KN/m) & $1.0 /-1.0$ & $32 /-38$ & $32 /-38$ \\
\hline Sloshing height(mm) & & & $2.0 / 0.0$ \\
\hline Impulsive base shear(KN/m) & & & $31 /-38$ \\
\hline Convect ive base shear $(\mathrm{KN} / \mathrm{m})$ & & & $2.0 /-2.0$ \\
\hline Impulsive base moment $(\mathrm{KN}-\mathrm{m} / \mathrm{m})$ & & & $144 /-118$ \\
\hline Convective base moment $(\mathrm{KN}-\mathrm{m} / \mathrm{m})$ & & & $7.0 /-7.0$ \\
\hline \multicolumn{4}{|c|}{ *The(-) sign indicates the response of system in opposite side of axis } \\
\hline \multirow{2}{*}{ Results } & \multirow{2}{*}{ Empty tank } & \multicolumn{2}{|c|}{ Full tank } \\
\hline & & No convective term & Sloshing effect \\
\hline Horizontal displacement(mm) & 5.6 & 14.3 & 14.2 \\
\hline Total base moment $(\mathrm{KN}-\mathrm{m} / \mathrm{m})$ & $144 /-143^{*}$ & $328 /-395$ & $310 /-393$ \\
\hline Total base shear(KN/m) & $34.5 /-35$ & $101 /-84$ & $101 /-77$ \\
\hline Sloshing height(mm) & & & $118 /-102$ \\
\hline Impulsive base shear(KN/m) & & & $90 /-92$ \\
\hline Convect ive base shear $(\mathrm{KN} / \mathrm{m})$ & & & $27 /-27$ \\
\hline Impulsive base moment $(\mathrm{KN}-\mathrm{m} / \mathrm{m})$ & & & $361 /-339$ \\
\hline Convective base moment $(\mathrm{KN}-\mathrm{m} / \mathrm{m})$ & & & $104 /-104$ \\
\hline
\end{tabular}

Separating the base moment and base shear to impulsive and convective terms, it can be seen that the same maximum results are obtained for impulsive and convective base shear under horizontal and horizontal + vertical excitations, while there are some differences between impulsive and convective base moment in two cases. In all the considered cases, exciting the model with vertical component of the earthquake lead to smaller results in comparis on with those obtained using horizontal or bi-component ground motions.

\section{Conclusions}

In the present paper, the staggered displacement method was utilized to consider seismic behaviour of liquid storage tanks. In the proposed method, liquid was modelled using rigorous finite element technique and damping effects due to impulsive and convective components of the stored liquid was modelled appropriately.

The fin ite element model of a typical tank-liquid system was developed while its base was considered to be rig id. An artificial dynamic load as well as a natural ground motion was selected to analysis of the system. In addition ABAQUS commercial software was chosen to verify the results of the proposed method without considering convective term in liquid domain.

The results show good consistency between ABAQUS and the proposed method, while ABAQUS leads to lower results. The main reason is related to different techniques used by ABAQUS and the proposed method for applying dynamic loads and implementing various components of damping and solving the coupled system. In addition the results of tank-liquid system with/without convective term were investigated. It was found that taking into account the free surface sloshing might affect the results. Under artificial dynamic load convective term increase result mean ingfully while El-Centro ground motion application leads to some reduction in total base shear and base moment which can be due to dynamic characteristics of the selected earthquake.

\section{REFERENCES}

[1] Housner, G.W., "Dynamic analysis of fluids in containers subjected to acceleration. Nuclear Reactors and Earthquakes", U. S. Atomic Energy Commission, Washington D.C., Tech. Rep. TID 7024, 1963.

[2] Haroun, M.A., Housner, G.W., "Dynamic Characteristics of Liquid Storage Tanks", Journal of Engineering Mechanics Division, ASCE EM 5, vol.108, 1982.

[3] Veletsos, A.S., "Seismic Response and Design of Liquid Storage Tanks, Guidelines for the Seismic Design of Oil and Gas Pipeline Systems", Technical Council on Lifeline Earthquake Engineering, ASCE, N.Y., 255-370, 443-461, 1984.

[4] Jaiswal, O.R., Kulkarni, S., Pathak, P., “A Study on Sloshing Frequencies of Fluid-Tank System", in Proceedings of $14^{\text {th }}$ World Conference on Earthquake Engineering, Beijing, China, 2008.

[5] Damatty, A.El., Korol R.M., Tang, L.M., "Analytical and Experimental Investigation of the Dynamic Response of Liquid-Filled Conical Tanks", in Proceedings of $12^{\text {th }}$ World Conference on Earthquake Engineering, Auckland, New Zealand, 2000. 
[6] Koh, H.M., Kim, J.K., Park, J.H., "Fluid-Structure Interaction Analysis of 3D Rectangular Tanks by a Variationally Coupled BEM-FEM and Comparison with Test Results", Earthquake Engineering and Structural Dynamics, vol.27, pp.109-124, 1998.

[7] Chen, J.Z., Kianoush, M.R., "Seismic Response of Concrete Rectangular Tanks for Liquid Containing Structures", Canadian Journal of Civil En gineering, vol.32, pp.739-752, 2004.

[8] Kianoush, M.R., Chen, J.Z., "Effect of Vertical Acceleration on Response of Concrete Rectangular Liquid Storage Tanks", Journal of Engineering Structures, vol.28, no.5, pp.704-715, 2004.

[9] Ghaemian, M., Kianoush, M.R. Mirzabozorg, H., "Time Domain Dynamic Analysis of Rectangular Liquid Containers in Three-Dimensional Space", European Earthquake Engineering, vol.2, pp.3-9, 2005.

[10] Kianoush, M.R., Mirzabozorg, H., Ghaemian, M., "Dynamic Analysis of Rectan gular Liquid Containers in Three-Dimensi onal Space", Canadian Journal of Civil Engineering, vol.33, pp.501-507, 2006.

[11] Gradinscak, M., Semercigil, S.E., Turan, Ö.F., "Liquid Sloshing in Flexible Containers, Part 2: Using a Sloshing Absorber with a Flexible Container for Structural Control", in Proceedings of $5^{\text {th }}$ International Conference on CFD in the Process Industries CSIRO, Melbourne, Australia, 2006.

[12] Livaoglu, R., Dogangun, A., "Simplified Seismic Analysis Procedures for Elevated Tanks Considering Flu id-StructureSoil Interaction", Journal of Fluids and Structures, vol.22, pp.421-439, 2006.

[13] Dong, Y., Redekop, D., "Structural and Vibrational Analysis of Liquid Storage Tanks", Transactions SMIRT 19, Toronto, Canada, 2007.

[14] Goudarzi, M.A. and Sabbagh-Yazdi, S.R., "Evaluating 3D Earthquake Effects on Sloshing Wave Height of Liquid Storage Tanks Using Finite Element Method, Journal of Seismology and Earthquake Engineering, vol.10, no.3, pp.123-136, 2008.

[15] Shahverdiani, K, Rahai, A.R., Khoshnoudian, F., "Fluid-Structure Interaction in Concrete Cylindrical Tanks under Harmonic Excitations", International Journal of Civil Engineering, vol.6, no.2, pp.132-141, 2008.

[16] Naderi, R., Yosefi Samangany, A., Talebpour, M.H., "Effect of Type of Earthquake Seismic Analysis of Concrete Cube Shaped Tanks Buried According to the Interaction of Soil Structure", in the Proceedings of $5^{\text {th }}$ SASTech Conference, Mashhad, Iran, 2011.

[17] James, D., Thanigaiarasu, G., "Seismic Analysis on Cylindrical Tanks Subjected to Horizontal Acceleration", International Journal of Applied Research in Mechanical En gineering, vol.1, no.1, 2011.

[18] Alembagheri, M., Estekanchi, H.E., "Nonlinear Analysis of Aboveground Anchored Steel Tanks Using Endurance Time Method", Asian Journal of Civil Engineering (Building and Housing), vol.12, no.6, pp.731-750, 2011.

[19] Mirzabozorg, H., Khaloo, A.R., Ghaemian, M., "Staggered Solution Scheme for Three Dimensional Analysis of Dam-Reservoir Interaction", The Journal of Dam Engineering, vol.14, no.3, pp.147-164, 2003.

[20] ABAQUS 6.5.1., Analysis User's Manual, 2006. 